JPL Publication 88-27

$$
\begin{gathered}
=\ldots+1 N-35-C R \\
\text { C.OLUR }
\end{gathered}
$$

DAPYEOUERPDE

$\$ 17648$

p.3

\title{
Millimeter-Wave Sensor Image Enhancement
}

\author{
William J. Wilson \\ Helmut Suess
}

September 15,1988

Prepared for

U.S. Army

Harry Diamond Laboratory

Through an agreement with

National Aeronautics and

Space Administration

by

Jet Propulsion Laboratory

California Institute of Technology

Pasadena, California 
TECHNICAL REPORT STANDARD TITLE PAGE

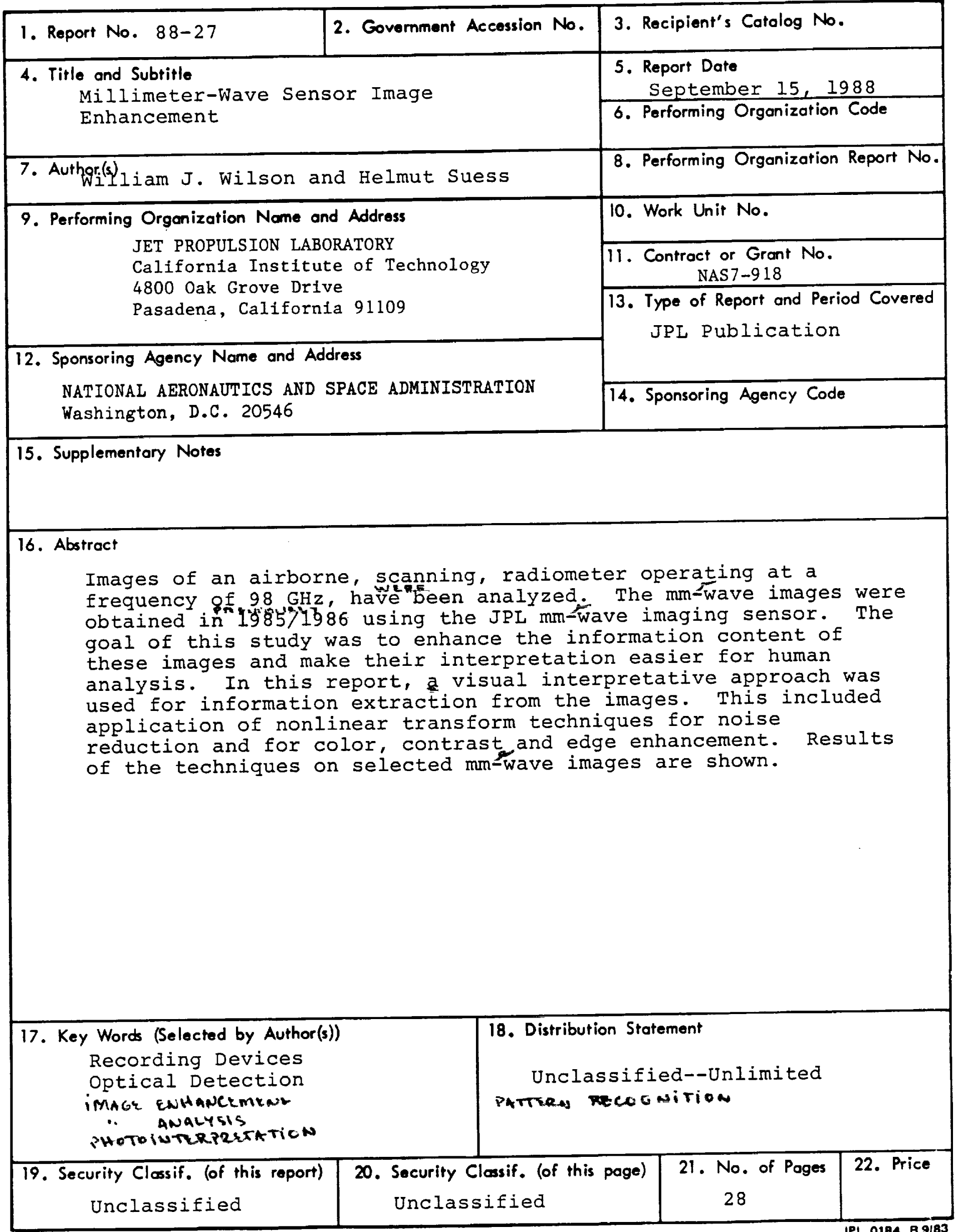


JPL Publication 88-27

\section{Millimeter-Wave Sensor Image Enhancement}

William J. Wilson Helmut Suess

September 15,1988

Prepared for

U.S. Army

Harry Diamond Laboratory

Through an agreement with

National Aeronautics and

Space Administration

by

Jet Propulsion Laboratory California Institute of Technology

Pasadena, California 
The research described in this publication was carried out by the Jet Propulsion Laboratory, California Institute of Technology, and was sponsored by the U. S. Army, Harry Diamond Laboratory through an agreement with the National Aeronautics and Space Administration. This work was done under JPL Task order No. RE-182 and Amendment No. 474, Change 1. This was funded by MIPR NO. R-86-111.

Reference herein to any specific commercial product, process, or service by trade name, trademark, manufacturer, or otherwise, does not constitute or imply its endorsement by the United states Government or the Jet Propulsion Laboratory, California Institute of Technology. 
Images of an airborne, scanning, radiometer operating at a frequency of $98 \mathrm{GHz}$, have been analyzed. The $\mathrm{mm}$-wave images were obtained in 1985/1986 using the JPL mm-wave imaging sensor. The goal of this study was to enhance the information content of these images and make their interpretation easier for human analysis. In this report, a visual interpretative approach was used for information extraction from the images. This included application of nonlinear transform techniques for noise reduction and for color, contrast and edge enhancement. Results of the techniques on selected mm-wave images are shown. 
CONTENTS

\section{CHAPTERS}

I. INTRODUCTION . . . . . . . . . . . . . . . . . . . . 1

II. BACKGROUND . . . . . . . . . . . . . . . . . . . 4

III. IMAGE PROCESSING TECHNIQUES - • • • • • • • • • • • • 9

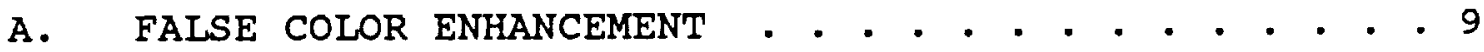
B. SMOOTHING . . . . . . . . . . . . . . . . . 11
C. BRIGHTNESS TEMPERATURE HISTOGRAM MODIFICATION • . 17
D. EDGE DETECTION . . . . . . . . . . . . . . . . 20

IV. CONCLUSIONS . . . . . . . . . . . . . . . . . . 25

ACKNOWLEDGMENTS . . . . . . . . . . . . . . . . 25

REFERENCES . . . . . . . . . . . . . . . . . 26

APPENDIX • . . . . . . . . . . . . . . . . . . 27 


\section{Figures}

2-1. Millimeter-wave radiometer observing a ground scene

from above. . . . . . . . . . . . . . . . . . 4

2-2. System configuration with the mm-wave sensor

mounted on a helicopter and showing the stabilized

raster scan on the ground. . . . . . . . . . . . 7

2-3. Simplified block diagram of the mm-wave imaging

sensor. . . . . . . . . . . . . . . . . 8

3-1. Transfer functions for the color map shown in Fig. 3-4

vs. pixel color intensity. . . . . . . . . . . . . 10

3-2. Video and $\mathrm{mm}$-wave images of a section of the $\mathrm{I}-5$ freeway south of Carlsbad, Ca., taken on a rainy day. The imager was flown over a layer of broken clouds as seen in (a). The area pictured in the $\mathrm{mm}$-wave image (b) is 0.4 by 2.4 $\mathrm{km}$. The image in (c) is contrast enhanced and the image in (d) has been processed with the sobel edge detection algorithm.

3-3. This image is the same as Fig. 3-2 with a different color map.

3-4. Visual and mm-wave images of the Agua Dulce Airport, southwest of Palmdale, Ca. The photograph in (a) and the $\mathrm{mm}$-wave data in (b) cover an area of 0.5 by $1.8 \mathrm{~km}$. The contrast enhanced image is in (c) and the edge detected image is in (d).

3-5. This image is the same as in Fig. 3-4 with a different color map. The original mm-wave data is in (a), the contrast enhanced image in (b) and the edge detected

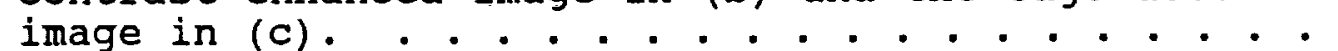

3-6. MM-wave images of a large ship in the long Beach, Ca. harbor just south of Terminal Island. The original data is in (a), and the smoothed data in (b) - (d) as explained in the text. . . . . . . . . . . . .

3-7. Diagram explaining the brightness temperature

histogram, $H(T)$, modification for the contrast enhancement algorithm.

3-8. Visual and $\mathrm{mm}$-wave images of military vehicles near Pulgas lake, Camp Pendleton, $\mathrm{Ca}$. The photograph in (a) and the mm-wave data in (b), cover an area of 0.6 by $1.8 \mathrm{~km}$. The contrast enhanced image is in

(c) and the edge detected image in (d) . . . . . . . . 
3-9. Visual and $m$-wave images of the Long Beach naval dock area. The photograph (a) and the mm-wave data (b) cover an area of $0.5 \mathrm{~km}$ by $2.0 \mathrm{~km}$. The contrast enhanced image is in (c) and the edge detected image in (d). . . . . . . . . . . . . . . . . . . . 23

3-10. MM-wave images of a large ship in the Long Beach, Ca. harbor just south of Terminal Island. The original data is in (a). The mm-wave data processed with the Laplace operator is in (b), the sobel operator in (c) and the Marr-Hildreth algorithm in (d). . . . . . 24

\section{Tables}

1-1. Surveillance Sensor Comparison . . . . . . . . . . . . 2

1-2. A Comparison of Approaches of the Interpretation of Digital Image Data... . . . . . . . . . . . 3

2-1. JPL Millimeter-wave Imaging Sensor Characteristics . . 8

3-1. Laplace and Sobel Operators . . . . . . . . . . . 20

A-1. Survey of Image Processing Programs . . . . . . . . . . 28 
Passive millimeter-wave sensors are very useful for battlefield surveillance because they provide information during foggy and cloudy weather when visual and IR sensors are unusable. This sensor can be used from an aircraft, helicopter, or from a ground based platform. One of the main advantages of the passive mm-wave imager, is that the interpretation of these images by human operators is similar to the interpretation of visual and IR images because of the high correlation between the intensities of adjacent points. This is in contrast to radar images which are complicated by speckle, polarization and edge backscatter effects.

Passive sensors have the advantage that the observations can be made without transmitting radiation. This reduces the possibility of being detected, destroyed, jammed or fooled as can happen with active radar sensors. However, radar sensors can provide high-resolution range and Doppler information which aids in target identification. Thus, a good surveillance system would use a passive sensor to survey the overall scene and then use the radar sensor in short bursts to help identify targets. A comparison between these passive and active sensors is summarized in Table 1-1.

One of the limitations of the passive mm-wave sensor is that it does not have the fine spatial resolution of visual and IR imageries. To help in the interpretation of this lower spatial resolution data, this study on mm-wave imaging data acquired by JPL in 1985 and 1986, was done to develop and apply special image processing techniques for the mm-wave images. There are two approaches which can be used for image information extraction. one approach, which makes use of the computer, is known as quantitative analysis or classification. The other approach, based on a visual inspection of an image by a human analyst, is known as photo or image interpretation: The properties of these approaches are summarized in Table 1-2[1]. Based on our experience with the mm-wave images, it was concluded that the photo interpretation approach is best for the evaluation of passive mm-wave images for battlefield surveillance. The shapes of important large scale features like roads, coastlines, rivers and other lineaments, which can be derived from mm-wave images as high contrast edges, are easier to interpret by a human analyst than by a computer. On the other hand the quantitative analysis approach can be considered complementary to aid in future automatic data analysis. 
Table 1-1. Surveillance Sensor Comparison

\begin{tabular}{|c|c|c|}
\hline Parameter & Passive - Radiometer & Active - Radar \\
\hline $\begin{array}{l}\text { Spatial } \\
\text { Resolution }\end{array}$ & Large: $5-10 \mathrm{~m}$ & Small: $1 \mathrm{~m}$ \\
\hline Identification & $\begin{array}{l}\text { Detection - Limited } \\
\text { classification }\end{array}$ & $\begin{array}{l}\text { Detection and } \\
\text { Recognition }\end{array}$ \\
\hline Range/Velocity & $\begin{array}{l}\text { Small: } 1 \mathrm{~km} \text { wide swath } \\
\text { Range: } \leq 2 \mathrm{~km}\end{array}$ & $\begin{array}{ll}\text { Large: } & -5 \mathrm{~km} \text { wide } \\
& \text { swath } \\
\text { Range: } & -10 \mathrm{~km}\end{array}$ \\
\hline $\begin{array}{l}\text { Image } \\
\text { Interpretation }\end{array}$ & $\begin{array}{l}\text { Easy to understand, } \\
\text { similar to visual - } \\
\text { changes in emissivity. } \\
\text { Correlates with visual } \\
\text { maps. }\end{array}$ & $\begin{array}{l}\text { Harder to understand } \\
\text { because of speckle, } \\
\text { aspect angle, depres- } \\
\text { sion angle and } \\
\text { polarization. }\end{array}$ \\
\hline & $\begin{array}{l}\text { Not sensitive to aspect } \\
\text { angle and polarization. } \\
\text { Real-time analysis } \\
\text { possible. }\end{array}$ & $\begin{array}{l}\text { Major returns from } \\
\text { edges and corner } \\
\text { reflectors. }\end{array}$ \\
\hline $\begin{array}{l}\text { Computer } \\
\text { Processing }\end{array}$ & $\begin{array}{l}\text { Simple image processing } \\
\text { techniques can be used } \\
\text { to assist observer. }\end{array}$ & $\begin{array}{l}\text { Large data set to } \\
\text { analyze. } \\
\text { Requires sophisticated } \\
\text { computer processing. }\end{array}$ \\
\hline Data Rate & Low: $\quad-100 \mathrm{kHz}$ & High: $\quad-1 \mathrm{MHz}$ \\
\hline security & $\begin{array}{l}\text { Undetectable - no } \\
\text { emission. } \\
\text { Difficult to jam - need } \\
\text { kwatts. Difficult to } \\
\text { spook, hard to } \\
\text { camouflage targets. }\end{array}$ & $\begin{array}{l}\text { Detectable RF emis- } \\
\text { sion, can be locked } \\
\text { on and destroyed. } \\
\text { can be jammed and } \\
\text { spooked. } \\
\text { can be fooled by } \\
\text { camouflage, corner } \\
\text { reflectors and } \\
\text { transponders. }\end{array}$ \\
\hline Equipment & $\begin{array}{l}\text { Relatively simple and } \\
\text { inexpensive. }\end{array}$ & $\begin{array}{l}\text { More complicated and } \\
\text { costly. }\end{array}$ \\
\hline
\end{tabular}


Table 1-2. A Comparison of Approaches of the Interpretation of Digital Image Data

Photointerpretation

(by human analyst)
Quantitative Analysis (by computer)
Occurs on a large scale relative to each pixel

Inaccurate area estimates

Limited multispectral analysis

Assimilate only a limited number of distinct brightness loads ( $\approx 16$ levels)

Shape determination is easy

Spatial information is easy to use in a qualitative sense
Occurs at individual pixel level

Accurate area estimates possible

Multispectral (multidimensional) analysis

Uses quantitatively all available brightness levels in all features (e.g. 256)

Shape determination involves complex software decisions

Limited techniques available for making use of spatial data

Image processing techniques which were found to be most useful, especially in real-time analysis, were the choice of the false color map, modification of the brightness temperature histogram for contrast enhancement, smoothing for noise reduction, and edge enhancement. These techniques are discussed in the following sections and examples using selected $\mathrm{mm}$-wave images are shown. 
When a mm-wave sensor observes a ground scene from above, as shown in Fig. 2-I, the received signal power or brightness temperature consists of thermal emission from objects in the antenna beam, reflected sky emission from these objects, and atmospheric emission from the atmosphere below the sensor:

$$
\mathrm{T}_{\text {rec }}=\mathrm{T}_{\text {obj }}+\mathrm{T}_{\text {ref }} \mathrm{sky}+\mathrm{T}_{\text {bckgnd }}+\mathrm{T}_{\text {atm }} \text { (K) }
$$

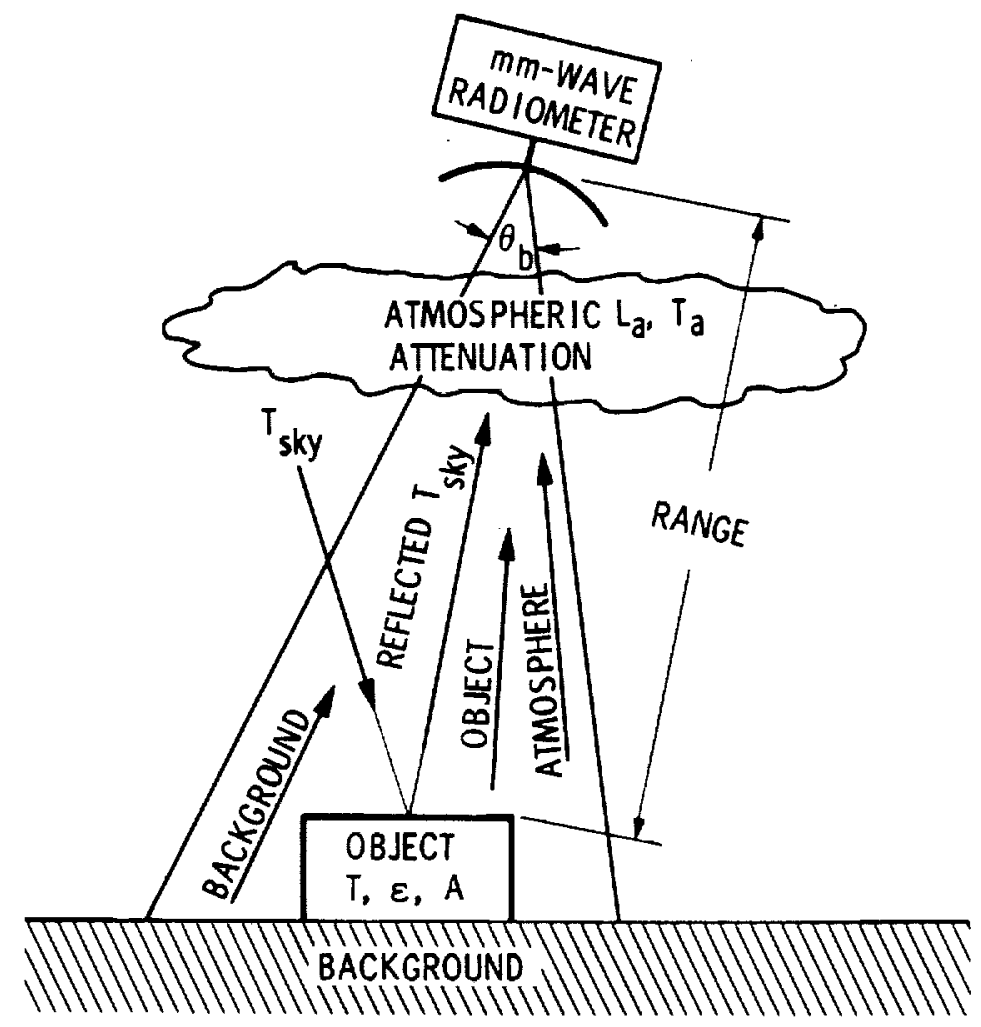

Figure 2-1. Millimeter-wave radiometer observing a ground scene from above

The received brightness temperature from objects in the antenna beam is equal to the product of its physical temperature and its surface emissivity, multiplied by the ratio of the object's area to the antenna's beam area and reduced by the atmospheric attenuation:

$$
\mathrm{T}_{\text {obj }}=\epsilon * \mathrm{~T} * \tilde{\mathrm{n}} / \mathrm{L}_{\mathrm{a}} \quad(\mathrm{K})
$$


where:

$\epsilon$

emissivity of the object and is a function of the material and its surface roughness $(0<e<1)$,

$\mathrm{T}$

physical temperature of the object (K),

$\mathrm{L}_{\mathbf{a}}$

atmospheric absorption factor below the radiometer, i.e., $=10 \mathrm{E}\left(\mathrm{L}_{\mathrm{atm}} * \mathrm{R} / 10000\right)$,

Latm

atmospheric attenuation $(\mathrm{dB} / \mathrm{km})$ below the radiometer,

$\mathbf{R}$

range to object (m),

$\tilde{\mathbf{n}}$

ratio of object's area to antenna beam area $(0<\tilde{n}<1), i . e ., A /(P I / 4)\left(R_{\tan ^{\theta}}{ }_{b}\right)^{2}$,

A

object's area (m2)

$\theta_{\mathrm{b}}$

antenna beamwidth (deg)

The reflected sky emission temperature is equal to the product of the radiometric sky temperature and the quantity $(1-\epsilon)$ and is also multiplied by the ratio of the object's area to the antenna's beam area and reduced by the atmospheric absorption:

$$
T_{\text {ref }} \text { sky }=(1-\epsilon) * T_{s k y} * \tilde{n} / L_{a} \quad(K),
$$

where:

$\begin{array}{ll}\mathrm{T}_{\mathrm{sky}} & \begin{array}{l}\text { radiometic sky temperature } \\ =\end{array} \\ \mathrm{T}_{\mathrm{atm}} *\left(1-1 / \mathrm{L}_{\mathrm{z}}\right)+\mathrm{T}_{\mathrm{cb}} / \mathrm{L}_{\mathrm{z}} \quad(\mathrm{K}) \\ \mathrm{L}_{\mathrm{z}} & \text { mean atmospheric temperature }(\approx 280 \mathrm{~K}), \\ \mathrm{T}_{\mathrm{cb}} & \text { cotal zenith absorption factor, } \\ & (=2.7 \mathrm{~K}) .\end{array}$

The received signal temperature from the background surrounding the object is given by:

$$
\left.\mathrm{T}_{\mathrm{bckgnd}}=\left(\epsilon_{g} * \mathrm{~T}_{\mathrm{g}}+\left(1-\epsilon_{\mathrm{g}}\right) * \mathrm{~T}_{\mathrm{sky}}\right) / \mathrm{L}_{\mathrm{a}}\right) *(1-\overline{\mathrm{n}})
$$

where $\epsilon_{\mathrm{g}}$ is the emissivity of the background and $\mathrm{T}_{\mathrm{g}}$ is the physical temperature of the background. The atmospheric emission below the radiometer is: 


$$
T_{\text {atmos }}=T_{a} *\left(1-1 / L_{a}\right) \quad(K),
$$

where $\mathrm{T}_{\mathrm{a}}$ is the physical temperature of the atmosphere below the radiometer.

MM-wave scenes can show large contrasts with reflecting objects, such as metal vehicles, buildings, or wet areas appearing much colder than the surrounding rough absorbing background. Thus, reflecting objects will "stand out" from the surrounding background with a large temperature difference or signal-to-noise ratio.

The system configuration used with this mm-wave imager is shown in Fig. 2-2, and a simplified block diagram is shown in Fig. 2-3. A complete technical description of the mm-wave imaging system was published in Ref. (2) and the characteristics are summarized in Table 2-1. In the mm-wave imaging sensor, a mechanical scanning system scans the $0.5^{\circ}$ antenna beam $\pm 22^{\circ}$ across the flight track. This beam is stabilized to correct for aircraft movement due to turbulence and uses a butterfly scanning pattern to produce a linear raster scan pattern on the ground as shown in FI.g. 2-2. This feature allows the mm-wave image to be displayed in real time. The operation frequency of $98 \mathrm{GHz}$ was chosen to give the smallest spatial resolution with the best poor weather performance. An altitude of $750 \mathrm{~m}$ was chosen as a typical value for battlefield surveillance and provides a ground resolution of $7 \mathrm{~m}$. If larger spatial resolutions can be used, the operating altitude could be increased. 


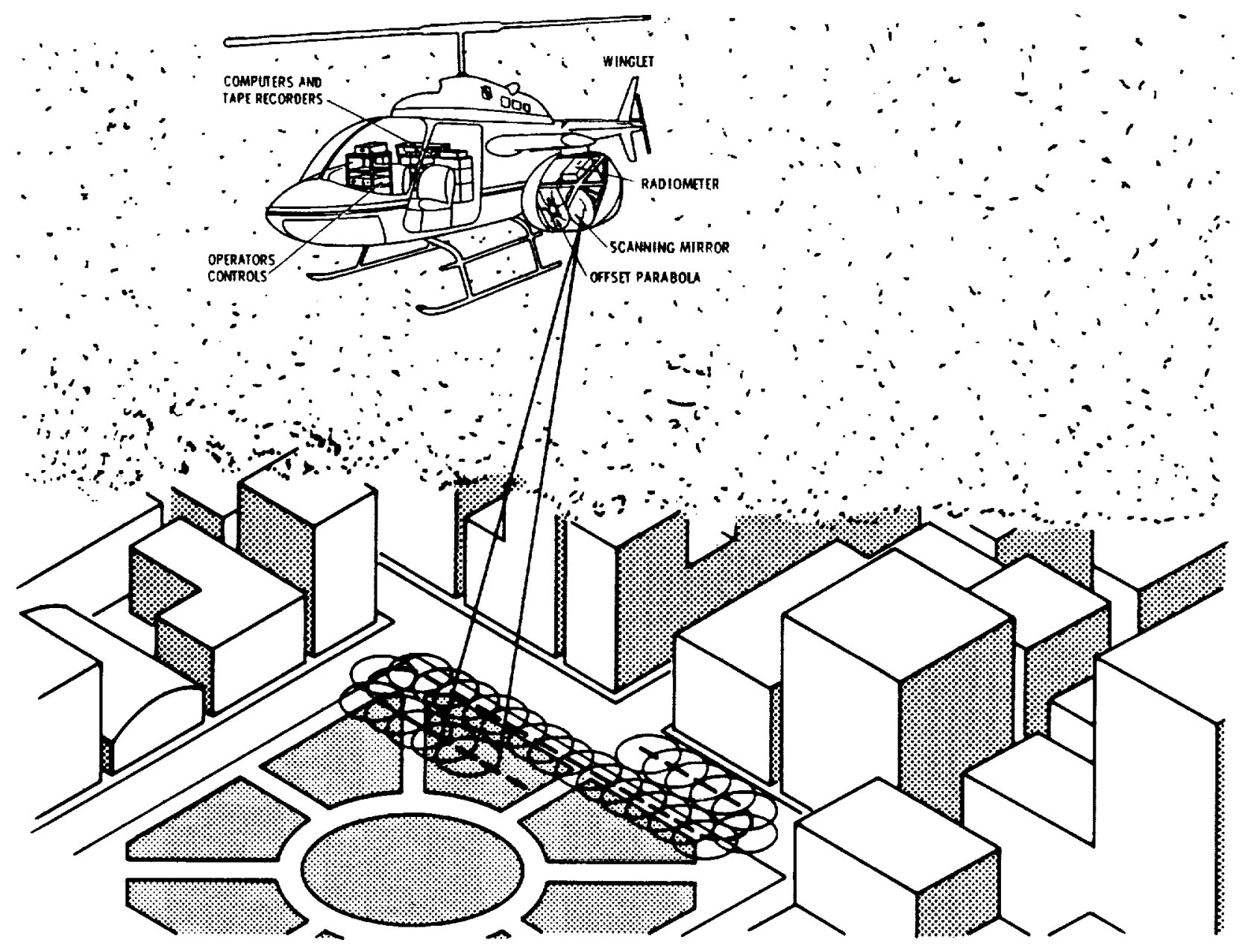

Figure 2-2. System configuration with the mm-wave sensor mounted on a helicopter and showing the stabilized raster scan on the ground 


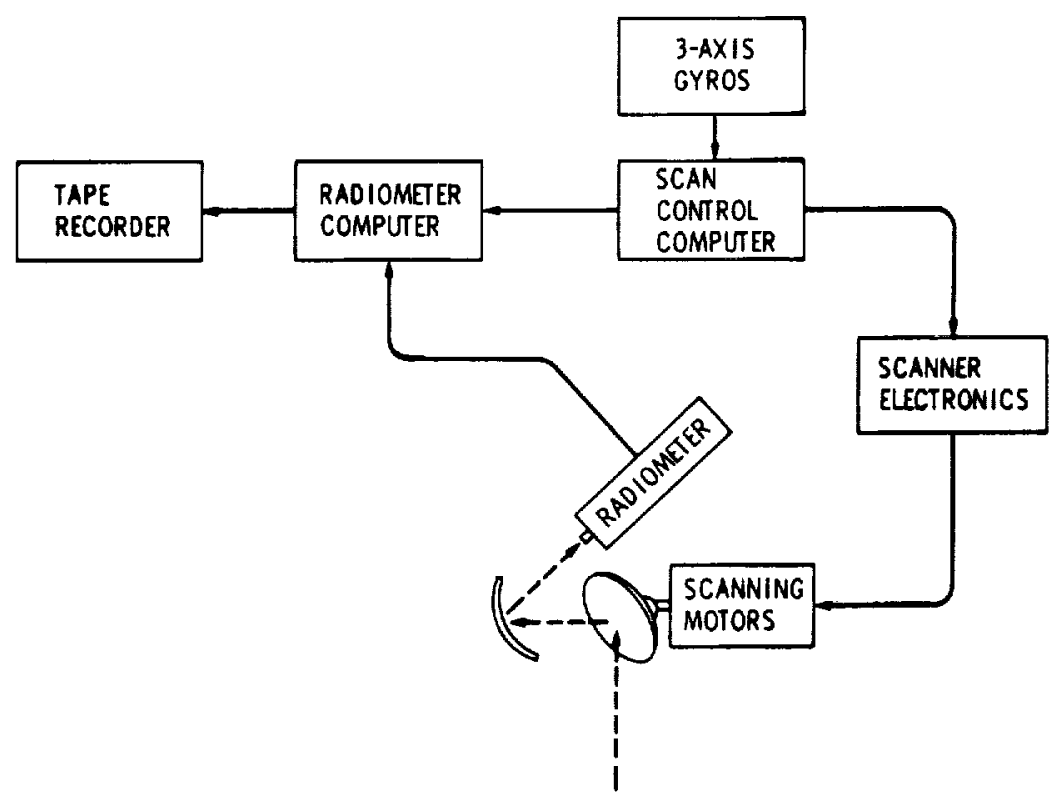

Figure 2-3. Simplified block diagram of the mm-wave imaging sensor

Table 2-1. JPL Millimeter-Wave Imaging sensor Characteristics

Aircraft Altitude

Aircraft speed

Scan width

Angular Resolution

Ground Resolution

Radiometer Type

Center Frequency

Sensitivity

Data Rate

Data Display

Weight

Power
$750 \mathrm{~m}$

$41 \mathrm{~m} / \mathrm{s}$ (kts)

$\pm 22.5^{\circ}$ or $620 \mathrm{~m}$

$0.5^{\circ}$

$<7 \times 7 \mathrm{~m}$

Total Power, Solid-state Dual Polarized

$98 \mathrm{GHz}$

$<0.8 \mathrm{~K}$

2800 samples per sec

False color TV image

$70 \mathrm{~kg}$

250 watts 


\section{CHAPTER III. IMAGE PROCESSING TECHNIQUES}

There are numerous types of image processing techniques which have been developed and described in the literature (Refs. $3,4,5,6)$. The goal of this study was to select the best algorithms for the processing of the lower spatial resolution high contrast mm-wave imaging data. These algorithms had to aid in the data analysis and be fast enough to operate in a real-time environment. After considerable study, a program package was developed for processing the mm-wave data. A summary of the image processing programs developed during this study and a detailed list of the menus are in the Appendix. The description of the techniques used on selected images is presented below. The images in this report were selected because they provided good examples for the demonstration of these techniques.

A.

\section{FALSE COLOR ENHANCEMENT}

The motivation for using color in image processing is the fact that the human eye can discern thousands of color shades and intensities. This is in sharp contrast with the eye's relatively poor performance with gray levels. Only about 16 shades of gray are detectable at any one point in an image by the average observer. Therefore, a color display has the capacity to convey much more information than an achromatic display and has the potential for improving the interpretability of images.

A careful selection of the false color scale for the brightness temperature range is an important item in the interpretation of the $\mathrm{mm}$ image. Letting the observer adjust the color scale and temperature range in real time gives excellent results in this analysis. One way to think of this is that each observer has a matched filter in his brain to process information, and being able to change the color scale to match this filter, will maximize the information transfer between the observer and the computer.

The color scale used in this report was generated empirically incorporating our former experience in data display. Normally colors can be represented by three dimensional vectors. If $C$ represents a given color and $\vec{R}, \vec{G}, \vec{B}$ represent the unit vectors of the three fixed primaries, then the equation

$$
C=\overrightarrow{R R}+G \vec{G}+B \vec{B}
$$

is used for the production of an additive mixture of the quantities $R, G, B$. In our case the tristimulus values $R, G, B$ were described by harmonic waves with varying amplitudes, frequencies and phases. The calculated and optimized transfer functions for $R, G, B$ are presented in Figure $3-1$ and the resultant color scale is shown in Figure 3-3. More sophisticated procedures which can also be used are described in Ref. 7 . 


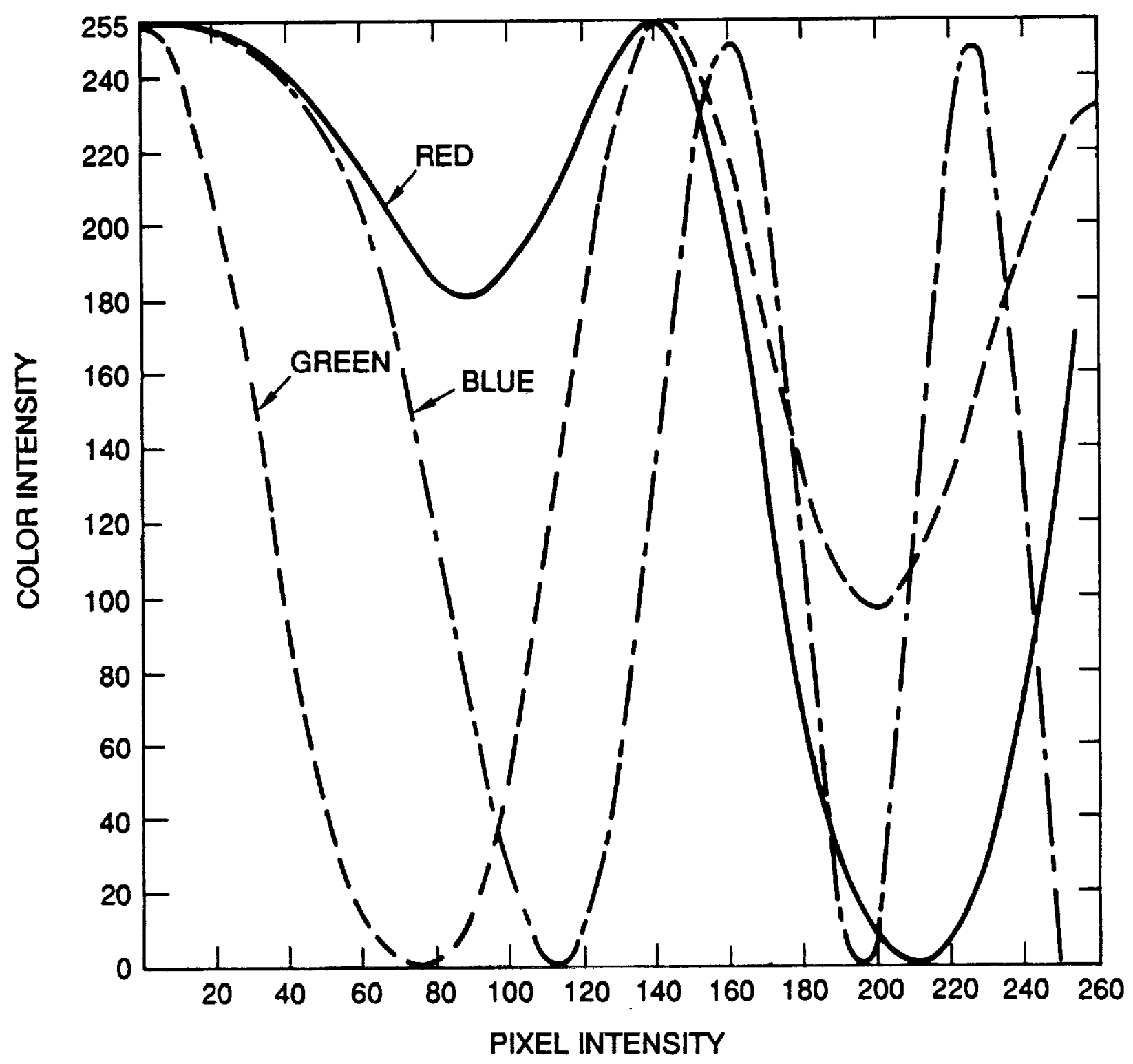

Figure 3-1. Transfer functions for the color map shown in Fig. 3.4 vs. pixel color intensity 
The image of the I-5 freeway near Carlsbad, Ca. on a partly cloudy day is shown in Fig. 3-2. Fig. 3-2a is the visual image and Fig. $3-2 b$ is the original mm-wave data with the false color scale adjusted to provide a realistic looking picture. This image is repeated in Fig. 3-3b, with a change in the color scale and gives a completely different impression of this scene. Choosing the color scale to appear similar to visual images seems to be one of the best choices to give the observer the best information transfer. Another example of the change in color scale is shown in Figs. $3-4 b$ and $3-5 a$, in an image of the Agua Dulce Airport. The more realistic looking scene in Fig. 3-5a is easier to understand and see the individual objects.

The key to selecting the best color scale is the ability to do this quickly and easily. In our current data reduction system, the color scale offset (the position of the color map on the brightness temperature scale) and the gain (the spread of colors vs brightness temperature) are quickly adjusted with a track ball to give the best image. Thus in a few minutes the best colors can be selected by each observer, and only minor changes are required for different images.

\section{B. SMOOTHING}

Smoothing algorithms reduce the random noise and other spurious effects that may be present in an image as a result of sampling, quantization or disturbances during image acquisition. These algorithms provide a better signal-to-noise ratio especially for distributed targets. However, the spatial resolution will be degraded and the edges are blurred. Three different smoothing algorithms were used on the original mm-wave ship image shown in Fig. 3-6a: a moving average, a median filter in the spatial domain, and a low pass filter in the spatial frequency domain.

The moving average filter (or neighborhood averaging) has the form:

$$
S^{\prime}(x, y)=(1 /(n * m)) \sum_{k=0}^{n-1} \sum_{1=0}^{m-1} s(x+k, y+1)
$$

where $S(x, y)$ is the input image and $S^{\prime}(x, y)$ is the output image. The moving average filter with a $3 \times 3$ window, $(\mathrm{n}=\mathrm{m}=3)$ was used on the original image and the result is shown in Fig. 3-6b. As seen, the image is quite blurred especially at the edges.

A median filter, in which the intensity of each pixel is replaced by the median of the intensities in a pre-defined neighborhood of that pixel, has the form:

$$
S^{\prime}(x, y)=\text { Median }(S(x, y), . . \cdot, S(x+k, y+1)),
$$



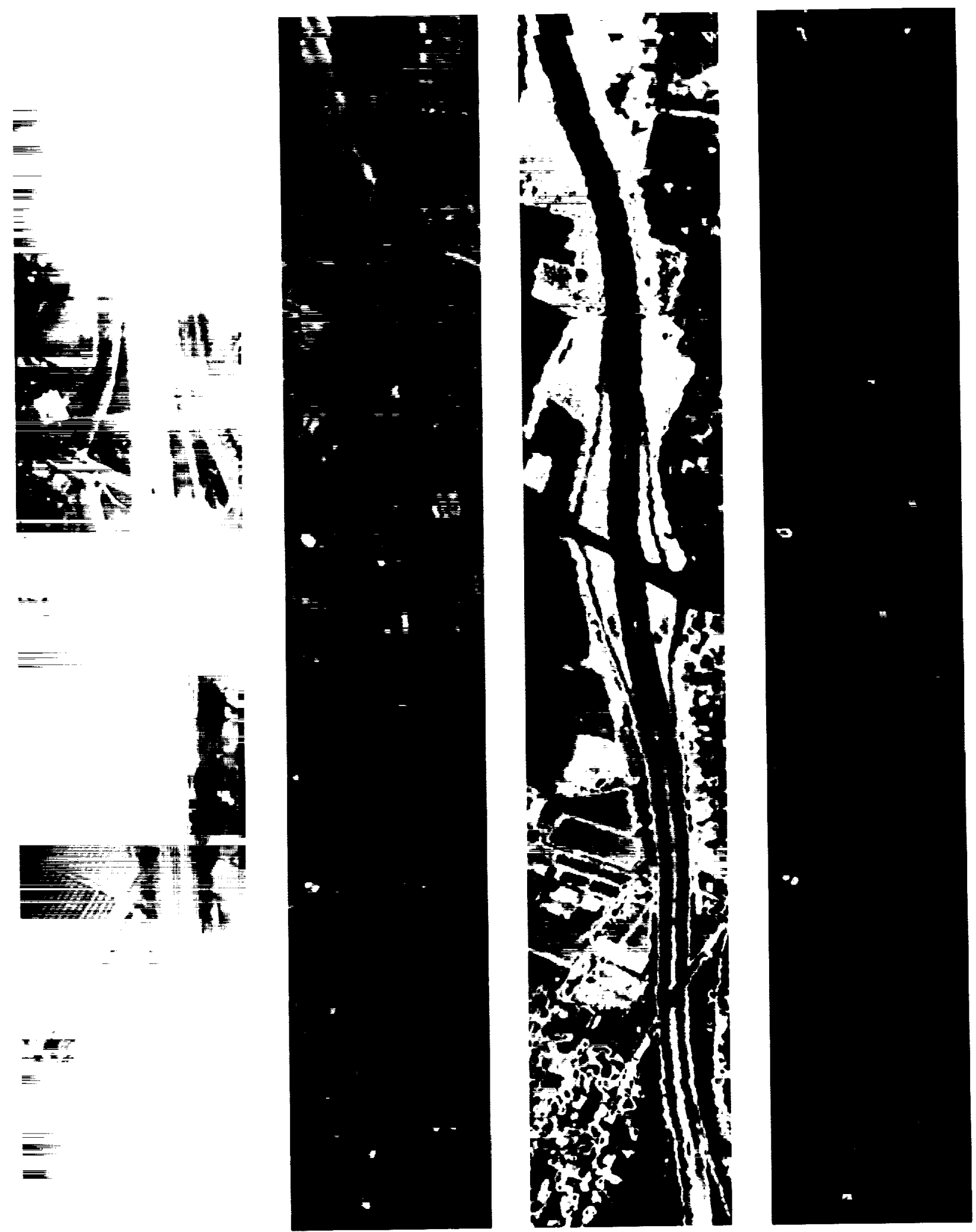

Figure 3-2. Video and mm-wave images of a section of the I-5 freeway south of Carlsbad, CA, taken on a rainy day. The imager was flown over a layer of broken clouds as seen in $(a)$. The area pictured in the $\mathrm{mm}$-wave image (b) is 0.4 by $2.4 \mathrm{~km}$. The image in (c) is contrast enhanced and the image in (d) has been processed with the Sobel edge detection algorithm. 

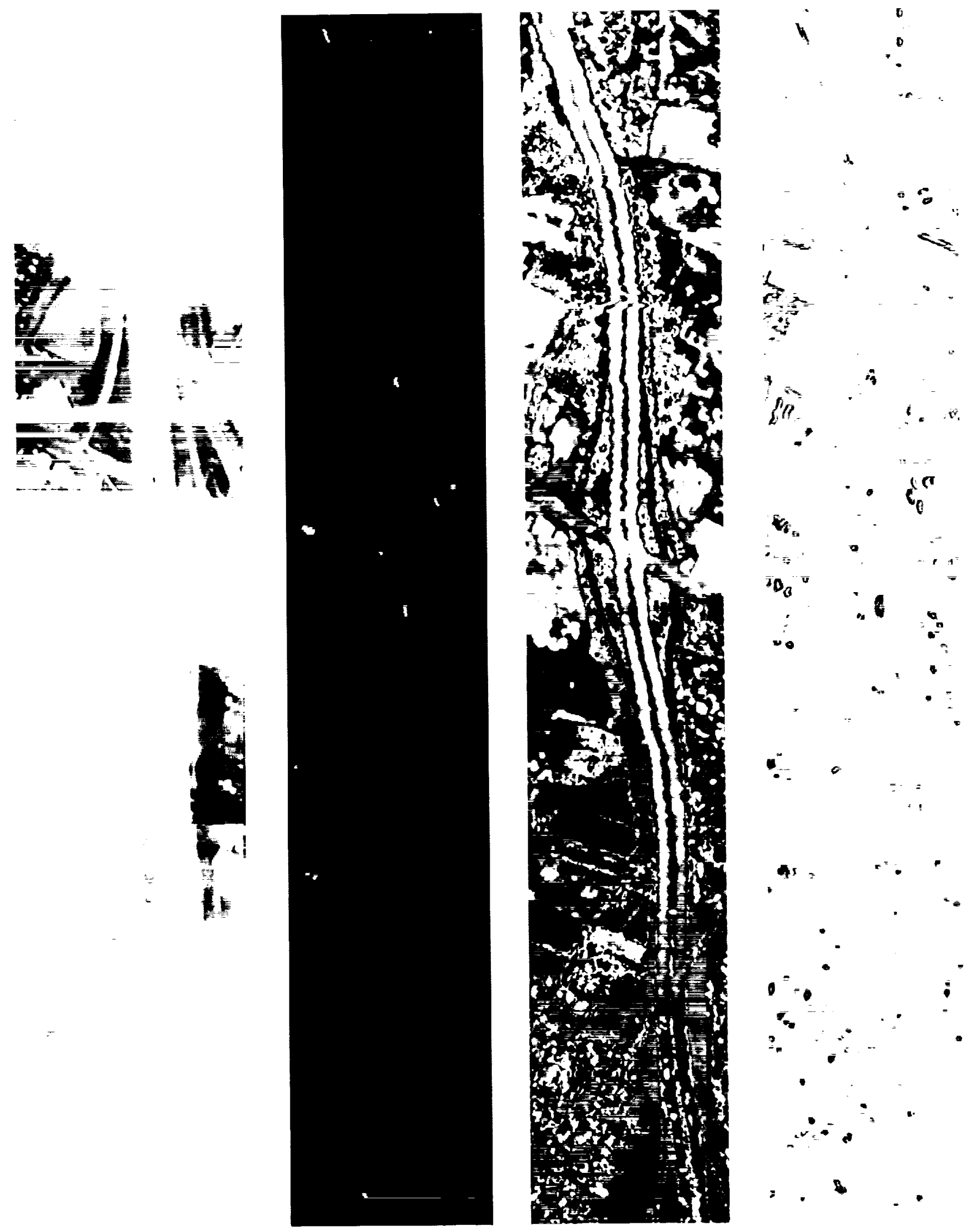

Figure 3-3. This image is the same as Fig. 3-2 with a different color map. 

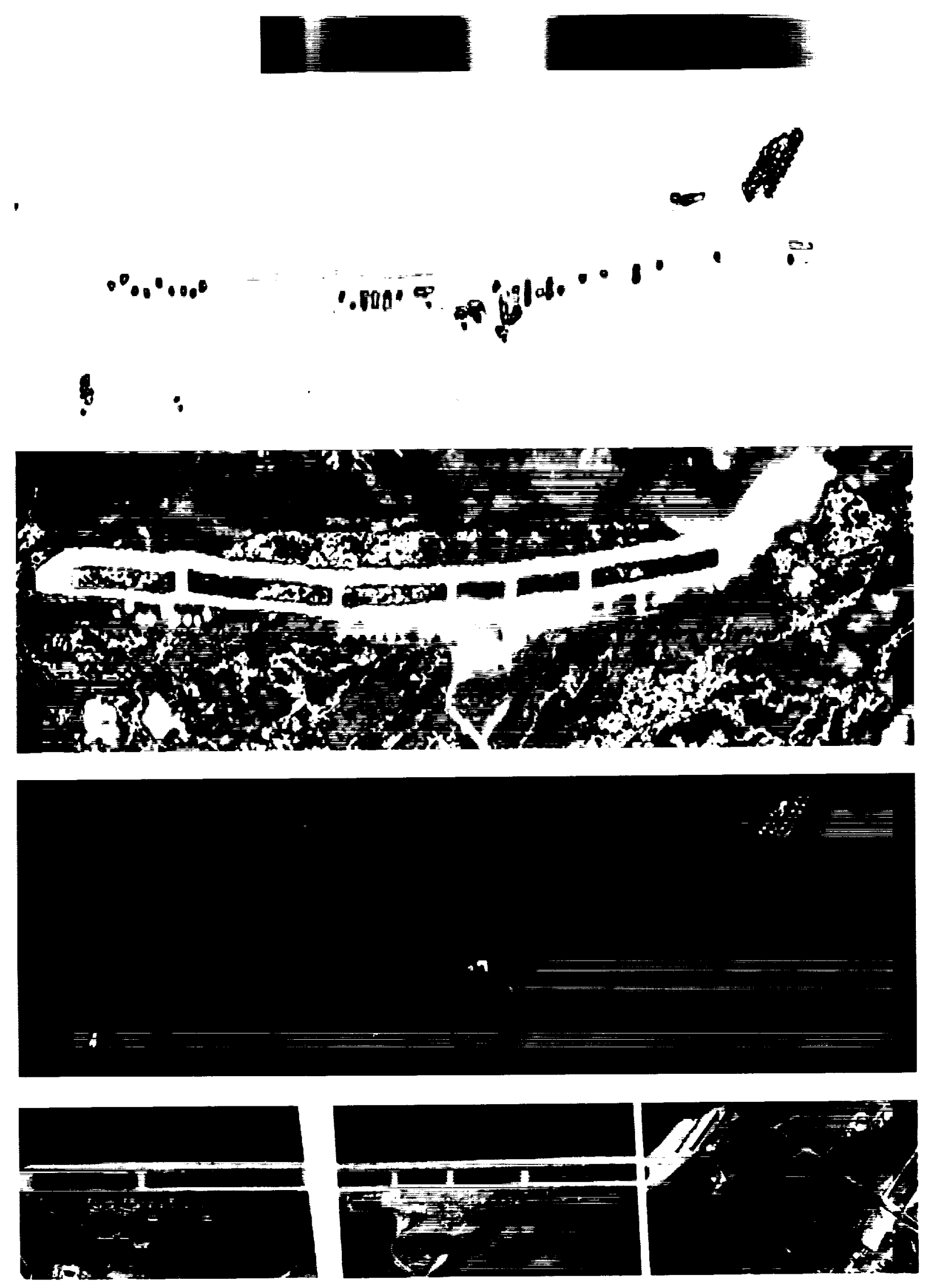

ORIGINAL PAGE
. E்

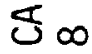

ஸ்

음

E约的

ron

4

400

ro

¿

的。

3

空

的品

엉

$\$$

$\sim 00$

ธ。

음

L-

$\bar{c}=0$

(1) $\div \frac{1}{5}$

용

范范

ช

西范

< 3

롵닽

+ $\sim$

$4 \frac{9}{4}$

ज 욤

ฮั

EO

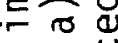

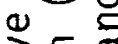

d.

3

1 둥

틍음

는

언

응

등

告

돋

ऽE

$j$
$\dot{1}$
d
$\frac{1}{3}$
$\frac{\sigma}{4}$ 


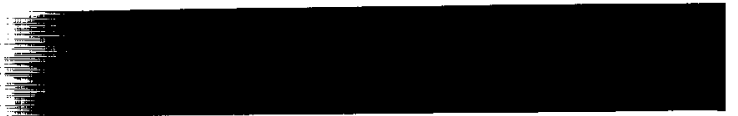

To

당

它 它

다

07

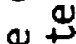

E
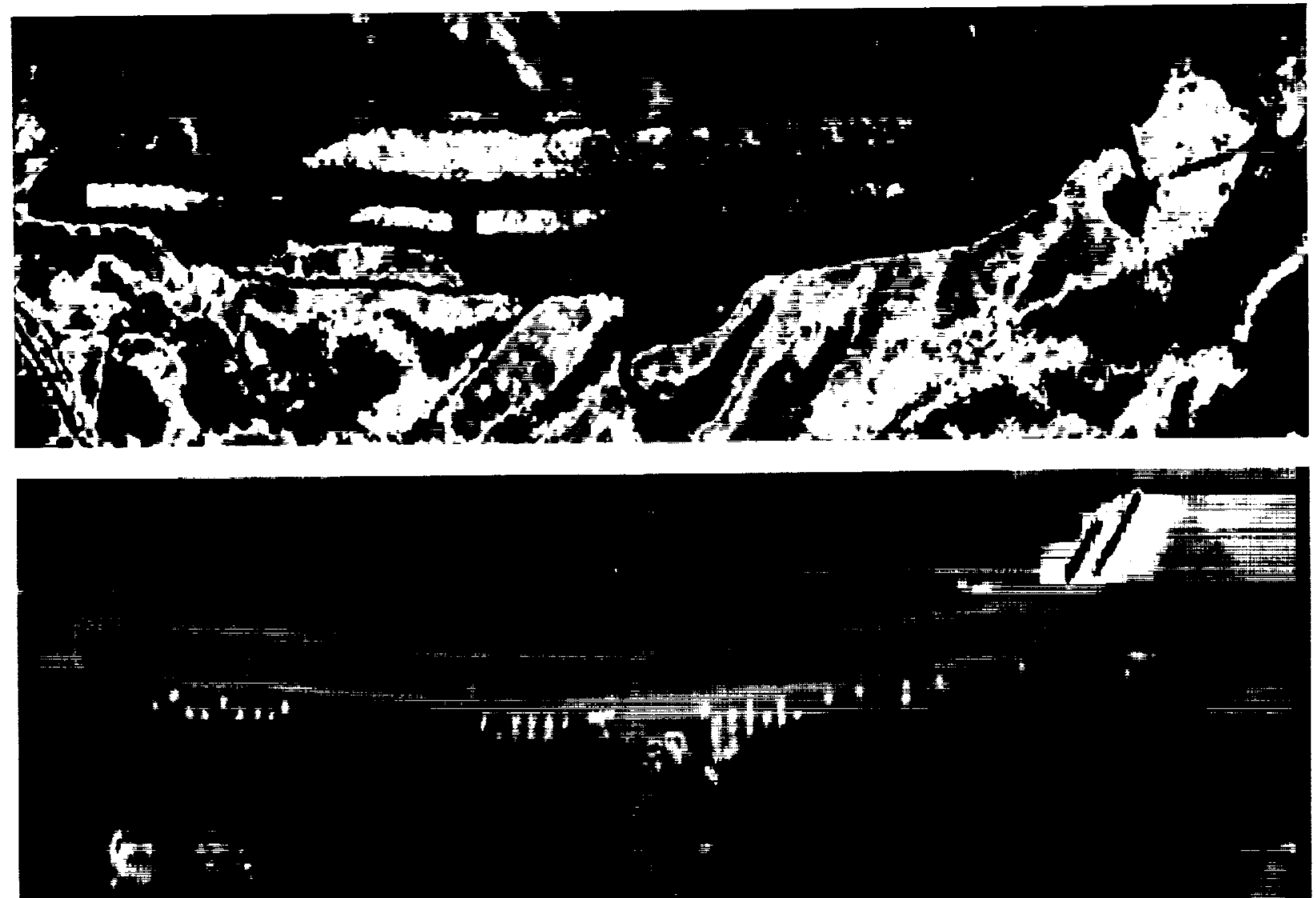

을

올

$\leqslant \frac{0}{0}$

으

언

$+$

Qิ

बे

40

둗

F

$\checkmark 0$

둥

员

$3 \cdot r$

$\checkmark$

$m \circlearrowleft$

- $\frac{E}{\sigma}$

$\sigma=$

느 ㄸ

$E+$

. n

$\sim \frac{1}{0}$

동

\&

原

( )

(1) $\frac{5}{5}$

$\frac{5}{3}$.

$\backsim \pi$

(1)

․․ㄷ

兽 n

$\cdot \pi$

$\sim q$

E

$n$
$m$
$\dot{1}$
$\frac{1}{3}$
$\frac{\pi}{4}$ 

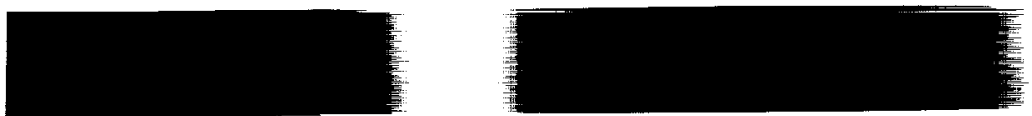

है.

क

$\leftarrow 0$

$4 \stackrel{\Phi}{=}$

$0 \cdot \frac{\pi}{2}$

돈 $\frac{0}{2}$
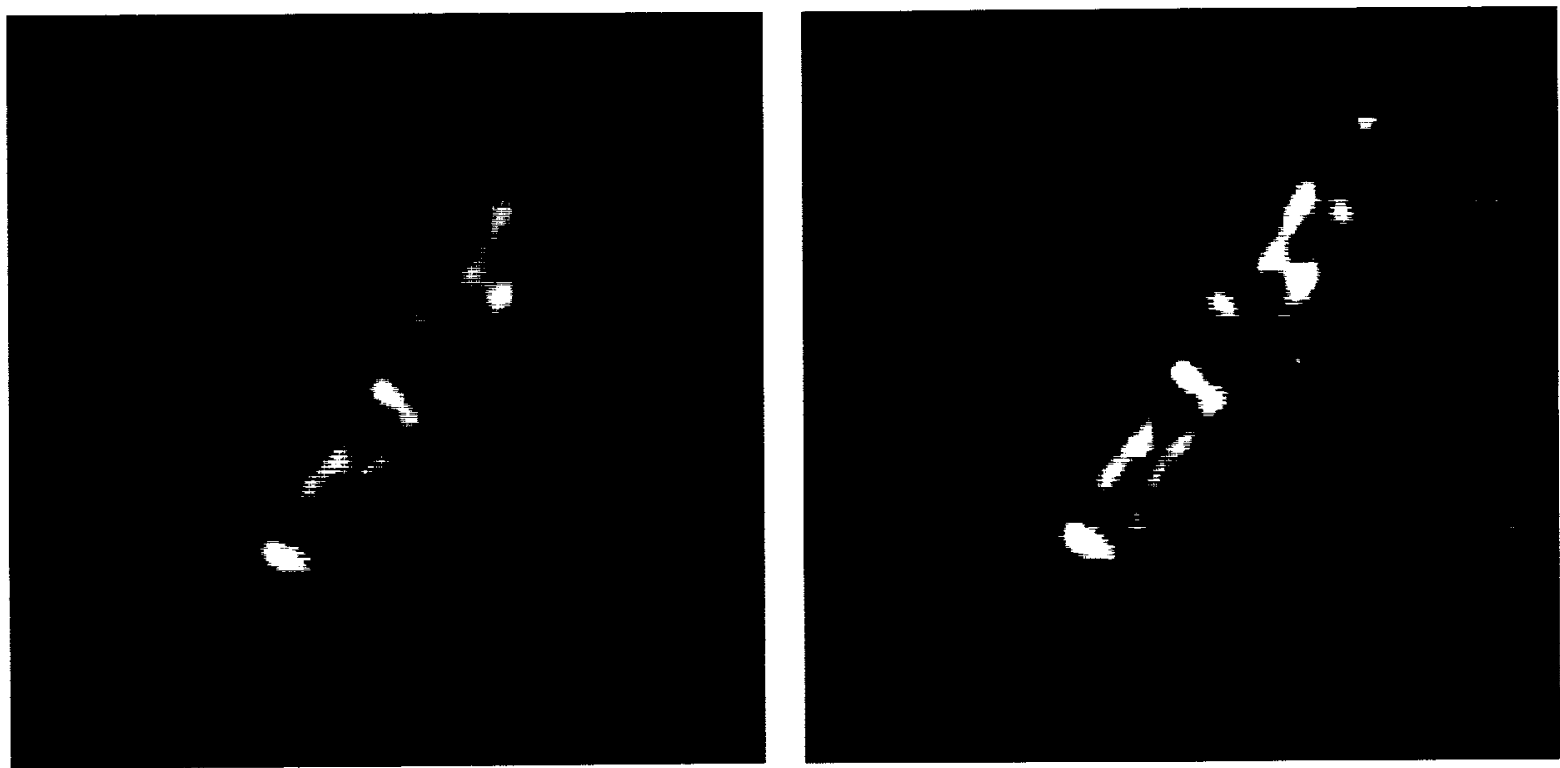

虽

$+\pi$

咨

光

1

응

10

$2=$

\&

.

ᄃ용

$\pi$

(1)

$\infty 4$

ㅁ. 뭉

58

$-\frac{2}{n}$

$\frac{d}{+} \frac{\Phi}{+\infty}$

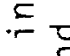

당

$\frac{\pi}{5}$

$\therefore \frac{1}{\pi}$

品

on

r.

ro $n$

$40+3$

थ

o

을

E E

o

$0_{0}^{1} 5$

3

$\sum_{2}^{\frac{1}{2}} \frac{0}{5}$

西

$m$

a

$\frac{9}{5}$ 
with $0<\mathrm{k}<\mathrm{n}-1$ and $0<1<\mathrm{m}-1$. The result of this algorithm (also with $n=m=3$ ) is shown in Fig. 3-5c. This image shows the reduction in noise and that there is less blurring than in the moving average image.

The third approach to smoothing was to low pass filter the image in the spatial frequency domain. The original image in frequency space, $S(u, v)$, was convolved with a low pass filter function $\mathrm{H}(\mathrm{u}, \mathrm{v})$ to reduce the high frequency noise:

$$
S^{\prime}(u, v)=H(u, v) * S(u, v) .
$$

The low pass filter function had the form:

$$
H(u, v)=1 /\left(1+0.4 *\left(\operatorname{Sqrt}\left(u^{2}+v^{2}\right) / D_{0}\right)^{2 \pi}\right) \text {, }
$$

where $D_{0}$ and $n$ are variables used to minimize the blurring effects. The results of this operation, with $D_{0}=4$ and $\mathrm{n}=1$, are shown in Fig. $3-6 \mathrm{~d}$.

A comparison of Figs. $3-6 c$ and $3-6 d$ shows only small differences. Thus it was concluded that the median filter, which is easier to implement for real time processing, is the best smoothing filter to use in the $\mathrm{mm}$-wave image processing because of the better edge preserving properties.

\section{BRIGHTNESS TEMPERATURE HISTOGRAM MODIFICATION}

Techniques of image enhancement have the goal to improve the visual appearance of an image and to convert the image to a form more amenable to human and machine analysis. Unfortunately, at the present time there exists no unifying theory of image enhancement since it is difficult to define a criterion characterizing a "good quality" image. One possible reason lies in the multiplicity of application fields. In our case, a technique which was found very useful was to equalize the brightness temperature histogram equalization or contrast enhancement (Ref. 4). This method is described in Fig. 3-7. The grey value histogram of the original image, which may have many of its pixels in a narrow temperature range, is mapped into a histogram with a nearly uniform distribution across the entire temperature range. After this modification, the cumulative distribution would be nearly a straight line. This means that an initial grey level interval with a high population will cause a larger stretch of the output grey levels than an interval with a lower population. Examples of images using this technique are shown in Figs. 3-2c through 3-5c, Fig. 3-8c and Fig. 3-9c.

This processing enhances larger areas while suppressing smaller objects. This resultant image is especially useful for enhancing distributed targets and identifying large scale geographic features such as types of vegetation, roads, and 


\section{HISTOGRAM MODIFICATION}

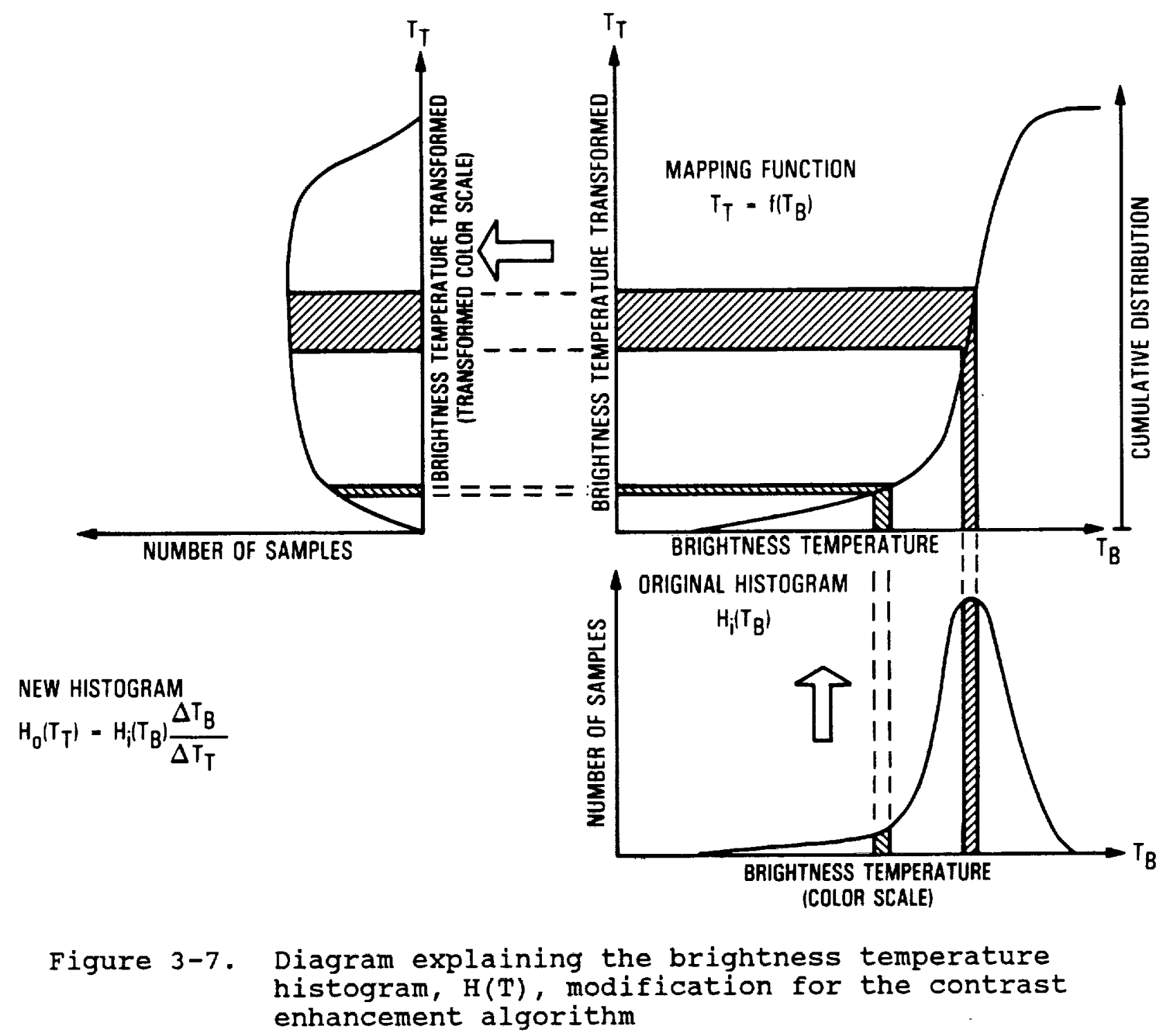


hills. An example of this is Fig. 3-8 which is an image of military vehicles in an open field at camp Pendleton. The small variations in the land area next to the road, Fig. 3-8b, are clearly emphasized in the contrast enhanced image in Fig. 3-8c. However, this technique suppresses small targets with only a few pixels. Thus, the vehicles in this image are difficult to detect.

Another good example of this technique is with the cloudy freeway scene in Fig. 3-1c. In this image the contrast enhancement makes it easy to see the freeway, the adjacent roads and the large fields near the freeway. Identifying these large areas is useful in determining the exact scene location. In the Agua Dulce Airport image, Fig. 3-4c, the changes in the terrain slope are easily scene. 


\section{EDGE DETECTION}

In $\mathrm{mm}$-wave images, boundaries of objects appear as brightness temperature or intensity discontinuities. For the human observer, an object can often be recognized from only a crude outline. To enhance the small objects and edges with high brightness temperature contrasts in the $\mathrm{mm}$-wave image, special edge enhancement algorithms are used. Two algorithms from the main class of gradient and template matching operators tried on this mm-wave data were the Laplace and the sobel operators. The formulas for these operators are given in Table 3-1. These operators reduce the temperature of all the pixels, except those on the border of a temperature discontinuity. The temperature increase at the object is proportional to the degree of the transition. Thus cold spots turn into hot doughnuts. The advantage of this algorithm is that it enhances small details that may not have been obvious on a uniform background.

Table 3-1. Laplace and Sobel Operators

\section{LAPLACE OPERATOR}

\begin{tabular}{|l|l|l|}
\hline & A2 & \\
\hline$A 8$ & A0 & A4 \\
\hline & A6 & \\
\hline
\end{tabular}

$$
G(X, Y)=4 * A 0-(A 2+A 4+A 6+A 8)
$$

\section{SOBEL OPERATOR}

\begin{tabular}{|c|c|c|}
\hline$A 1$ & $A 2$ & $A 3$ \\
\hline$A 8$ & G & A4 \\
\hline$A 7$ & $A 6$ & $A 5$ \\
\hline
\end{tabular}

$$
\begin{aligned}
& X=(A 1+2 * A 2+A 3)-(A 7+2 * A 6+A 5) \\
& Y=(A 1+2 * A 8+A 7)-(A 3+2 * A 4+A 5) \\
& G(X, Y)=\sqrt{X^{2}+Y^{2}}
\end{aligned}
$$


Based on tests with many mm-wave images, it was determined that the sobel operator gave the best results for small objects. Examples using the edge detection algorithm are shown in Figs. 3-2d through 3-5d, 3-8d,3-9d and 3-10c. In the cloudy freeway scenes, Figs. $3-2 d$ and $3-3 d$, this processing highlights the small vehicles and the edges of the roads. In Fig. 3-8d, the military vehicles stand out against the smooth background, making it easy to count them and to identify their formation. In the Long Beach Navy dockyard scene in Fig. 3-9, the image is very complicated, and the edge detection in this form does not aid in the analysis.

One additional edge detection algorithm which is useful for distributed targets is the Marr-Hildreth technique (Ref. 10) which can be used to outline targets. This could be helpful with computers to automate the image analysis using object recognition algorithms. The first step in this technique is to smooth the image by convolving it with a Gaussian distribution:

$$
G(x, y)=\exp \left(-\left(x^{2}+y^{2}\right) / 2 * P i * \sigma^{2}\right)
$$

where $\sigma$ is the size of the smoothing area. The second step of this process is a convolution with the Laplacian of the twodimensional Gaussian:

$$
2 G(x, y)=-1 /\left(P i * \sigma^{4}\right) *\left(1-\left(x^{2}+y^{2}\right) * \exp \left(-\left(x^{2}+y^{2}\right) / 2 \sigma^{2}\right)\right.
$$

The third step is to find the zero-crossings and draw a line. An example of this is shown with the ship image in Fig. 3lod. In this case the major structures of the ship are outlined, which could help in its identification. The limitation on this technique though, is that the targets must be large enough ( $\approx 100$ pixels) to give recognizable shapes. A further disadvantage is that this operator is isotropic because of the symmetry of the Laplacian. Better results can be obtained with so-called anisotropic operators (for example see Ref. 11). 

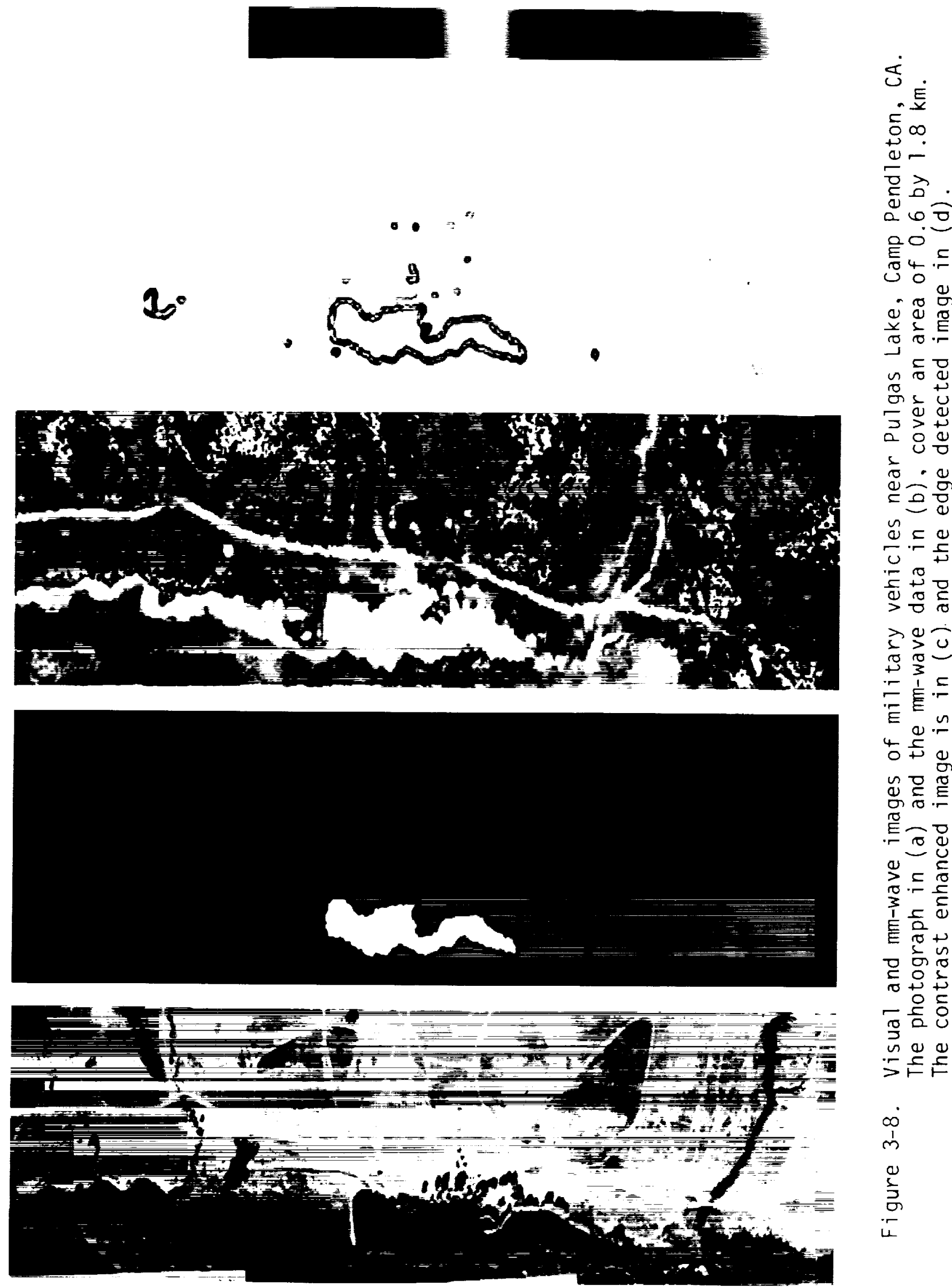

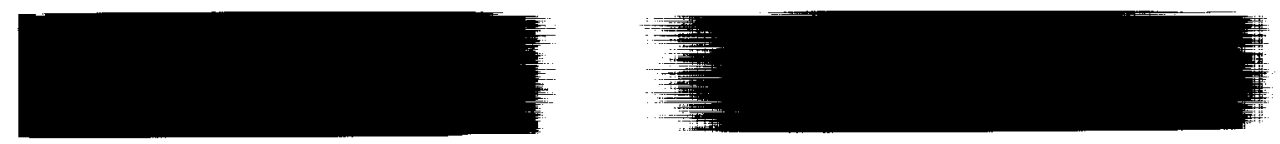

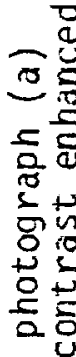
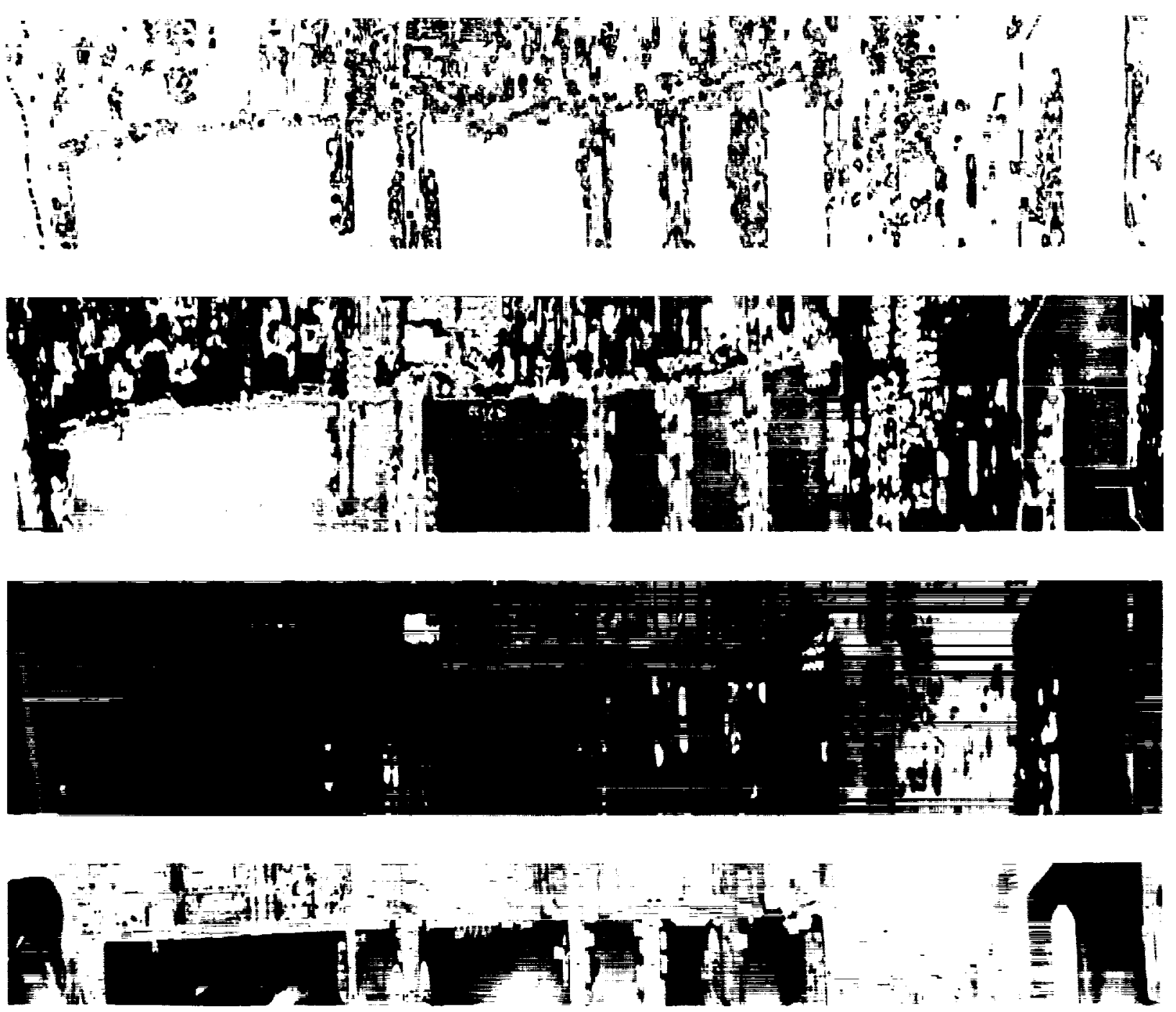

$\stackrel{ㅁ}{F}$

过

:

윰

Tृ

边

与

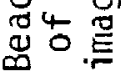

ตึับ

官宁过

Q 5 宁

th

4 号

๙

응

五正

$\Phi \stackrel{+口}{0}$

栗

等

을

万車岳

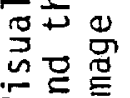

$5 \frac{2}{3}$

i

皆 


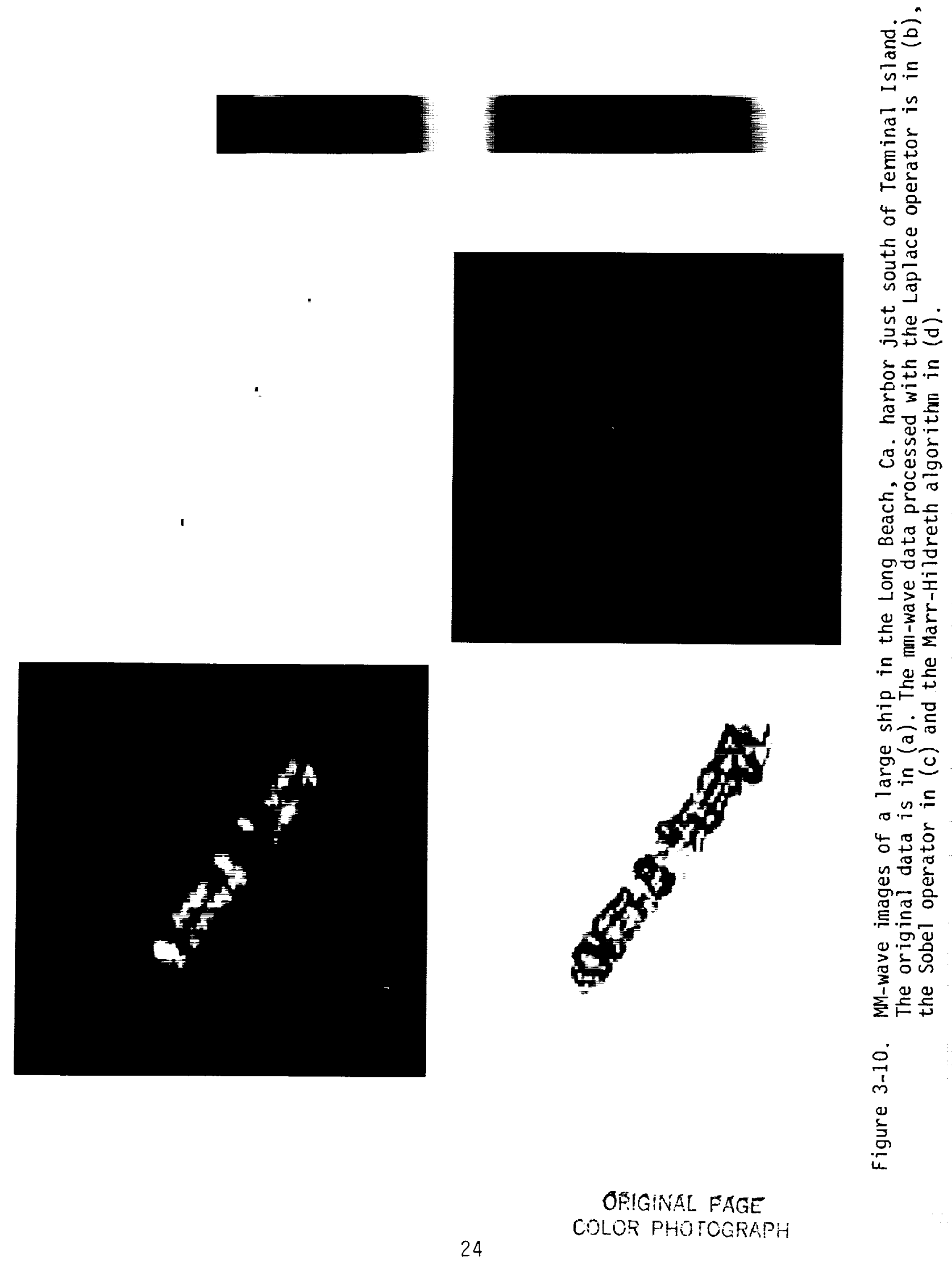


CHAPTER IV. CONCLUSIONS

In this study, techniques of color scale choice and

adjustment on the brightness temperature scale, modification of the brightness temperature histogram, and edge detection techniques have been found to be very effective in the visual interpretation of the mm-wave images. Other techniques of smoothing and outlining were found not to aid in the analysis except in specialized cases. The display of the original mmwave data along with the contrast enhanced and the edge detection images appears to be a good combination to assist an observer in the interpretation of this data. The observer can also adjust the color scale and gain factors using his intuition to bring out the details to understand the image. Having this information in real time is important in the usefulness of this data. Enhancing this data may lead to future steps to get computer recognition of the images.

\section{ACKNOWLEDGMENTS}

The authors thank Daren Casey, Fred Burnette, Mike Kobrick and Diane Evans for their advice and support. 


\section{REFERENCES}

1. J. A. Richards, "Remote Sensing Digital Image Analysis," Springer-Verlag, Berline Heidelberg, New York, 1986, p. 69.

2. W. J. Wilson, R. J. Howard, A. C. Ibbott, G. S. Parks and W. B. Ricketts, "Millimeter-wave Imaging Sensor," IEEE Trans. Microwave Theory Tech., Vol. MTT-34, p. 1026-1035, Oct. 1986.

3. R. C. Gonzalez and P. Wintz, Digital Image Processing, Addison Wesley, Reading Mass. 1977.

4. W. K. Pratt, Digital Image Processing, New York: WileyInterscience, 1978.

5. E. L. Hall, Computer Image Processing and Recognition, Academic Press, New York, 1982.

6. A. Rosenfeld, A. C. Kak, Digital Picture Processing, Academic Press, New York, 1982.

7. G. Wyszecki, W. S. Stiles, Color Science, Wiley, New York, 1982 .

8. Bimbaca, K. C. Smith, Design and Implementation of a Color Vision Model for Computer Vision Applications, Computer Vision Graphics and Image Processing, 39, $226-$ 245 (1987).

9. H. Suess, "New Results of Airborne Measurements with Cryogenic, High Resolution, Radiometric Imaging systems at $90 \mathrm{GHz}$ and $140 \mathrm{GHz}$, Ninth International Conference of Infrared and Millimeter Waves, Takarazuka, Oct. 22-16, 1984.

10. D. Marr, E. Hildreth, Theory of Edge Detection, Proc. R. Soc. London, B207, 187-217, (1980).

11. T. Canny, "A Computational Approach to Edge Detection," IEEE Transactions on Pattern Analysis and Machine Intelligence, Vol. PAMI-8, No. 6, Nov. 1986, p. 679-698. 


\section{APPENDIX}

Summary of the MM-Wave Image Processing Program Package

To use this program package as summarized in the Table $A-1$, the following comments are necessary:

- Files

Each image consists of a header file - specified by $\mathrm{xxx \times xx}$ INF - and a data file - specified by $x \times x \times x \times$ DAT.

- Data File

The image data are written with the JPL-subroutines DKREAD and DKWRIT (using corresponding VAX-VMS sub-routines) on and from disk.

- Header File

Each header consists of the following three numbers: number of image lines, number of samples per image line, and the specification of the data type ( $1^{*}$ two byte integer data, $2^{\text {* }}$ byte data). The header data are written in the following FORTRAN - format: 3 I6.

- Greyman, Filter, Edge

There are listed more functions in the menus than described in Chapter 3. The mathematical background for these algorithms is described for Greyman in [4], for FILTER and EDGE in [3]. 
Table A-1. Survey of Image Processing Programs

$\begin{array}{ll}\text { Function Display an Irage } & \text { Load, Change and } \\ \text { Loaded an Disk } & \text { Manipulate Color } \\ & \text { Table }\end{array}$

\begin{tabular}{|c|c|c|c|}
\hline Progran & DISPTMAGE & & CSCDISP \\
\hline Menu & & & \\
\hline & DTSPIAY RAW TMAGES & [1] & EXIT \\
\hline & ZOOM OF TMPAGES & [2] & ADTUST CENIER \\
\hline & DISFLAY SUB-TMAGES & [3] & AND GET CIOR \\
\hline & DISPLAY A NEW IMAGE & [4] & MAP FROM DISK \\
\hline & SAVE $1034 * 1024$ IMAGES & [5] & FUIE \\
\hline & DISPIAY $1024 * 1024$ IMAGES & {$[6]$} & CREATE A NEW \\
\hline & SAVE $1280 * 1024$ TMACES & [7] & COLOR MAP \\
\hline & DISPLAY $1280 * 1024$ IMAGES & [8] & FUT COLOR MAP \\
\hline & SAVE SUB-TMAGE FROM & [9] & aN DISK \\
\hline & SOREEN CURSOR & {$[10]$} & \\
\hline & EXIT & [11] & \\
\hline
\end{tabular}

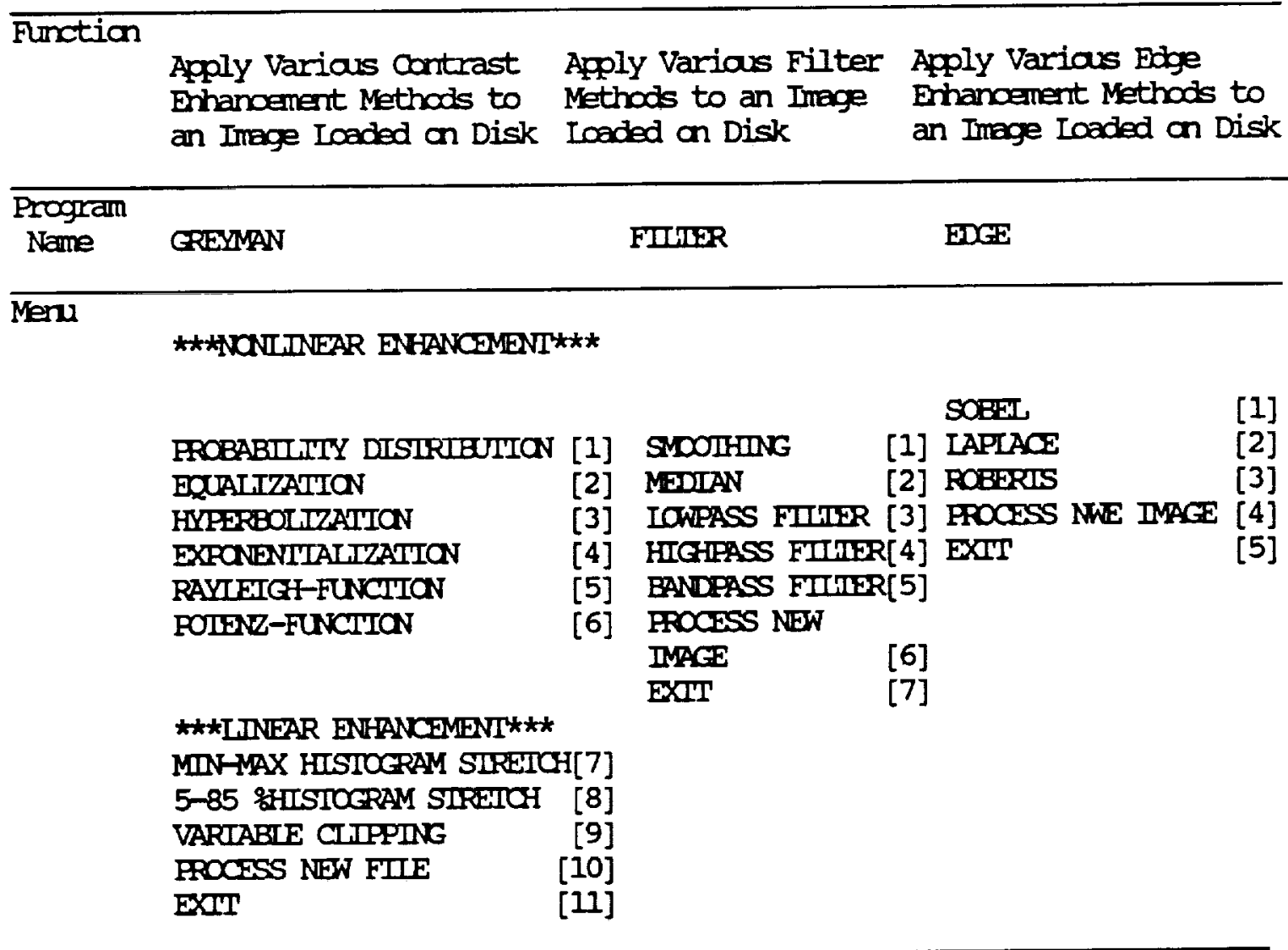

